\title{
SOURCES, VERTICAL FLUXES AND ACCUMULATION OF ALIPHATIC HYDROCARBONS IN COASTAL SEDIMENTS OF THE RIO DE LA PLATA ESTUARY, ARGENTINA
}

Colombo, J.C. ${ }^{1,2}{ }^{*}$, Cappelletti, N. ${ }^{1,2}$, Lasci, J. ${ }^{1}$, Migoya, M.C. ${ }^{1,3}$, Speranza, E. ${ }^{1,2}$, Skorupka, C.N. ${ }^{1}$

${ }^{1}$ Laboratorio de Química Ambiental y Biogeoquímica, Facultad de Ciencias Naturales y Museo, Universidad Nacional de La Plata, Av. Calchaqui km 23500 (1888) Florencio Varela, Buenos Aires, Argentina laqab@intervar.com.ar

${ }^{2}$ Comisión de Investigaciones Científicas, Provincia de Buenos Aires.

${ }^{3}$ Consejo Nacional de Investigaciones Científicas y Técnicas

\footnotetext{
* Corresponding author
} 
Table 2. Total sediment (Sed), carbon (TOC), resolved aliphatic (RES) and unresolved complex mixture (UCM) fluxes measured in the Río de la Plata compared with other environments.

\begin{tabular}{|c|c|c|c|c|c|c|}
\hline Environment & $\begin{array}{c}\text { Trap/bottom } \\
\text { depth (m) }\end{array}$ & $\begin{array}{l}\text { Sed } \\
\left(\mathrm{g} \cdot \mathrm{m}^{2}\right.\end{array}$ & $\begin{array}{l}\text { TOC } \\
\left.\cdot d^{-1}\right)\end{array}$ & $\begin{array}{l}\text { RES } \\
\text { (mg.n }\end{array}$ & $\begin{array}{l}\text { UCM } \\
\left.n^{2} \cdot d^{-1}\right)\end{array}$ & References \\
\hline Lake Michigan & $35 / 83$ & 0.5 & 0.02 & 0.07 & & (19) \\
\hline Dabob Bay & $60 / 110$ & 3.7 & 0.24 & 0.05 & 0.33 & $(15,20)$ \\
\hline Puget Sound & $50-100 / 205$ & 2.5 & 0.09 & 0.06 & 1.5 & (21) \\
\hline Saint Lawrence & $150 / 250$ & 6.8 & 0.26 & 0.16 & 0.69 & $(17,18)$ \\
\hline off San Diego & $55 / 60$ & 79.9 & 1.8 & 0.27 & & (22) \\
\hline Off Sta. Maria & $\begin{array}{c}104-211 / \\
105-212\end{array}$ & 36.8 & 0.64 & 0.59 & 2.43 & (23) \\
\hline Rio de La Plata & $1.5 / 5$ & 360.9 & 29 & 37 & 319 & This study \\
\hline
\end{tabular}


Table 3. Hydrocarbon inventories and sediment trap inputs in the coastal area of the Río de la Plata.

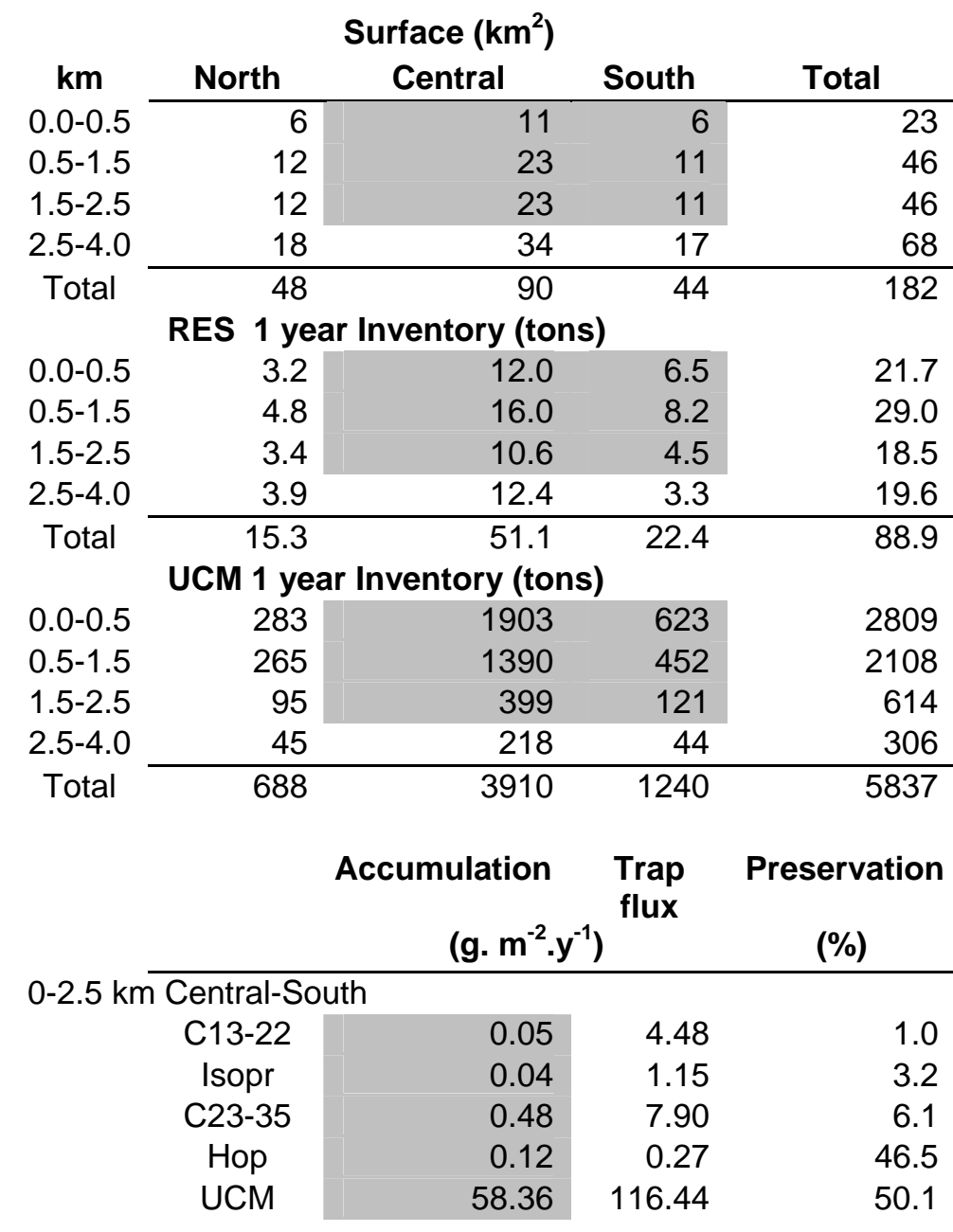

Total input 0-2.5 km Central-South

$\begin{array}{lrrr}\text { RES } & 58 & 1162 & 5.0 \\ \text { UCM } & 4888 & 9751 & 50.1\end{array}$

